\title{
Vitamin D and risk of cause specific death: systematic review and meta-analysis of observational cohort and randomised intervention studies
}

\author{
(c) (1) (8) OPEN ACCESS
}

\begin{abstract}
Rajiv Chowdhury cardiovascular epidemiologist ${ }^{1}$, Setor Kunutsor PhD candidate $^{1}$, Anna Vitezova PhD candidate ${ }^{2}$, Clare Oliver-Williams PhD candidate ${ }^{1}$, Susmita Chowdhury research associate ${ }^{3}$, Jessica C Kiefte-de-Jong postdoctoral scientist ${ }^{2}$, Hassan Khan cardiovascular epidemiologist ${ }^{1}$, Cristina P Baena assistant professor ${ }^{4}$, Dorairaj Prabhakaran professor ${ }^{5}$, Moshe B Hoshen professor ${ }^{6}$, Becca S Feldman professor ${ }^{6}$, An Pan assistant professor ${ }^{78}$, Laura Johnson lecturer ${ }^{9}$, Francesca Crowe nutritional epidemiologist ${ }^{10}$, Frank B Hu professor ${ }^{7}$, Oscar H Franco professor ${ }^{2}$
\end{abstract}

\begin{abstract}
'Department of Public Health and Primary Care, University of Cambridge, Strangeways Research Laboratory, Cambridge CB1 8RN, UK; ${ }^{2}$ Department of Epidemiology, Erasmus MC, Rotterdam, The Netherlands; ${ }^{3}$ Public Health Genomics Foundation, Cambridge, UK; ${ }^{4}$ Pontifícia Universidade Católica do Paraná, Brazil; ${ }^{5} \mathrm{Centre}$ for Chronic Disease Control, New Delhi, India; ${ }^{6} \mathrm{Clalit}$ Research Institute and Chief Physician's Office, Clalit Health Services, Israel; ${ }^{7}$ Department of Nutrition, Harvard School of Public Health, Boston, Massachusetts, US; ${ }^{8}$ National University of Singapore, Republic of Singapore; ${ }^{9}$ School for Policy Research, University of Bristol, UK; ${ }^{10}$ Cancer Epidemiology Unit, University of Oxford, Oxford, UK
\end{abstract}

\section{Abstract}

Objective To evaluate the extent to which circulating biomarker and supplements of vitamin $\mathrm{D}$ are associated with mortality from cardiovascular, cancer, or other conditions, under various circumstances. Design Systematic review and meta-analysis of observational studies and randomised controlled trials.

Data sources Medline, Embase, Cochrane Library, and reference lists of relevant studies to August 2013; correspondance with investigators.

Study selection Observational cohort studies and randomised controlled trials in adults, which reported associations between vitamin $\mathrm{D}$ (measured as circulating 25 -hydroxyvitamin $D$ concentration or vitamin $D$ supplement given singly) and cause specific mortality outcomes.

Data extraction Data were extracted by two independent investigators, and a consensus was reached with involvement of a third. Study specific relative risks from 73 cohort studies (849 412 participants) and 22 randomised controlled trials (vitamin $\mathrm{D}$ given alone versus placebo or no treatment; 30716 participants) were meta-analysed using random effects models and were grouped by study and population characteristics.

Results In the primary prevention observational studies, comparing bottom versus top thirds of baseline circulating 25 -hydroxyvitamin $D$ distribution, pooled relative risks were 1.35 ( $95 \%$ confidence interval 1.13 to 1.61 ) for death from cardiovascular disease, 1.14 (1.01 to 1.29) for death from cancer, 1.30 (1.07 to 1.59) for non-vascular, non-cancer
\end{abstract}

death, and 1.35 (1.22 to 1.49 ) for all cause mortality. Subgroup analyses in the observational studies indicated that risk of mortality was significantly higher in studies with lower baseline use of vitamin $D$ supplements. In randomised controlled trials, relative risks for all cause mortality were 0.89 ( 0.80 to 0.99$)$ for vitamin $D_{3}$ supplementation and 1.04 (0.97 to 1.11) for vitamin $D_{2}$ supplementation The effects observed for vitamin $D_{3}$ supplementation remained unchanged when grouped by various characteristics. However, for vitamin $D_{2}$ supplementation, increased risks of mortality were observed in studies with lower intervention doses and shorter average intervention periods.

Conclusions Evidence from observational studies indicates inverse associations of circulating 25-hydroxyvitamin $\mathrm{D}$ with risks of death due to cardiovascular disease, cancer, and other causes. Supplementation with vitamin $D_{3}$ significantly reduces overall mortality among older adults; however, before any widespread supplementation, further investigations will be required to establish the optimal dose and duration and whether vitamin $D_{3}$ and $D_{2}$ have different effects on mortality risk.

\section{Introduction}

Vitamin D is a group of fat soluble vitamins responsible for intestinal absorption of calcium and phosphate. ${ }^{1}$ Two major forms of vitamin D exist. Vitamin $\mathrm{D}_{2}$ (ergocalciferol), found in plants, is produced by ultraviolet $\mathrm{B}$ irradiation of ergosterol and can be consumed as a supplement or in fortified foods. ${ }^{2}$ Vitamin 
$\mathrm{D}_{3}$ (cholecalciferol), on the other hand, a product of ultraviolet $B$ irradiation of 7-dehydrocholesterol, is synthesised in the human epidermis or consumed in the form of natural (for example, fish) or fortified food sources or as a supplement. ${ }^{2}$ Supplementation with vitamin D has been shown to benefit skeletal conditions such as rickets, fractures, and falls, ${ }^{3-5}$ although a similar effect on bone mineral density was not evident in a recent review of trials. ${ }^{6}$ A growing body of evidence indicates that vitamin D may reduce risks of a wide range of diseases including multiple sclerosis, autoimmune disorders, infections, and cardiometabolic and cancer outcomes, ${ }^{7-12}$ indicating a possible pleiotropic effect across extraskeletal systems. However, the evidence for vitamin D reducing the risk of non-skeletal diseases is still being debated. ${ }^{13}$

Suboptimal concentrations of vitamin D have also been implicated as a potential determinant of mortality because of its wide ranging anti-inflammatory and immune modulating effects. ${ }^{214}{ }^{15}$ However, available observational studies examining this intriguing link are yet to be rigorously reviewed, and the extent to which vitamin D deficiency confers risk of death from cardiovascular disease, cancer, or other conditions remains uncertain. Although several individual reports and reviews have been published on the topic, ${ }^{16-21}$ they vary greatly and lack sufficient detail (for example, associations for diverse causes of death or primary versus secondary prevention settings). Additionally, interpretation of the earlier quantitative reviews of randomised trials is difficult, ${ }^{18}{ }^{21}$ as they typically include studies with mixed interventions (for example, combined with calcium intake, which has been associated with cardiovascular risk $^{22}$ ) and lack detailed assessments to distinguish the effects across important characteristics (such as geographical location, intervention dosage and duration, and follow-up time). A need exists, therefore, for an adequately powered, comprehensive assessment of associations of vitamin D concentrations with the risk of mortality across primary and secondary prevention settings and from a broad range of causes. This is of particular importance because estimates of mortality risk remain a cornerstone in formulating health policies to prevent or reduce premature deaths and improve quality of life, and in this sense vitamin D might play a key role.

In this study, we have aimed to summarise the available observational and interventional evidence in one updated systematic review and meta-analysis to (a) determine the associations of 25-hydroxyvitamin concentrations with the risk of cause specific mortality outcomes in observational cohort studies; (b) quantify the effects of vitamin D supplementation (overall and by subtypes), when given alone compared with placebo or no treatment, on mortality outcomes in the randomised controlled trials; and (c) examine all associations under a wide range of study level characteristics.

\section{Methods}

\section{Data sources, search strategy, and eligibility criteria}

We did this review according to a predefined protocol and in accordance with the PRISMA and MOOSE guidelines (eAppendix 1 and 2). ${ }^{23}{ }^{24}$ Two independent authors, in duplication, sought studies published before 1 August 2013 (date last searched) using Medline, Embase, and Cochrane databases. The computer based searches combined terms related to the exposure (such as vitamin D, 25-hydroxyvitamin D) and outcomes (such as mortality, all cause mortality, death), without any language restriction. Details of the search strategy are provided in eAppendix 3. We sought studies that had reported on associations of circulating vitamin $\mathrm{D}$ (measured as 25-hydroxyvitamin D) or vitamin D supplements with all cause mortality (defined as deaths from any causes) or cause specific mortality (defined as deaths due to cardiovascular disease, cancer, and other causes), in which fatal outcomes were registered according to the primary cause (or, in its absence, the underlying cause), on the basis of coding from the international classification of diseases or according to study defined classifications; ascertainment was based on death certificates.

\section{Study selection}

Observational cohort studies were eligible for inclusion if they assessed association of circulating 25-hydroxyvitamin D concentration with cause specific or all cause deaths in adults, and recruited participants from either of the following categories: general populations - that is, participants not selected on the basis of pre-existing chronic disease, including cardiovascular, metabolic, malignant, or renal disorders (that is, primary prevention cohorts); or people with pre-existing baseline conditions mentioned above (that is, secondary prevention cohorts). Intervention studies were eligible if they were randomised; assessed effects of vitamin D supplements singly (that is, randomised controlled trials with a "vitamin D alone" intervention group) in adults compared with a placebo or no treatment; and collected cause specific or all cause mortality endpoints (as defined before). Two independent reviewers worked together to screen the titles and abstracts of all initially identified studies according to the selection criteria. Full texts were retrieved for studies that satisfied all selection criteria. We searched reference lists of selected studies and relevant systematic reviews on the topic for additional publications.

\section{Data extraction}

Two independent authors extracted data, and a consensus was reached with involvement of a third. We used a predesigned data abstraction form to extract relevant information. This included questions on study size, study design, baseline population, location, age at baseline, duration of follow-up, reported degree of adjustment (defined as "+" when relative risks were adjusted for established cardiovascular risk factors such as age, sex, smoking status, lipids, hypertension, history of cardiometabolic disease; "++" when adjusted for other potential risk factors such as physical activity, body mass index, social status; and "+++" when additionally adjusted for other additional variables such as bone minerals), type and numbers of mortality outcomes, and reported relative risks. Where appropriate, we extracted information on subtypes of vitamin D supplement, number of participants in the supplement and control groups, baseline circulating vitamin D concentration, assay method, blinding status, and composition of supplement or placebo. If risk estimates were unavailable from a published report, we collected relevant data by corresponding with the authors, ${ }^{25-27}$ abstracting from other published reviews, ${ }^{192} 28$ or hand calculating on the basis of the available information from the paper, ${ }^{29-31}$ where appropriate. Additionally, in the case of multiple publications, we included the most up to date or comprehensive information. $^{32} 33$

\section{Assessment of risk of bias}

For observational cohort studies, we used the Newcastle-Ottawa Scale to assess the risk of bias. ${ }^{34}$ This scale uses a star system (with a maximum of nine stars) to evaluate a study in three domains: selection of participants, comparability of study groups, and the ascertainment of outcomes of interest. We 
judged studies that received a score of nine stars to be at low risk of bias, studies that scored seven or eight stars to be at medium risk, and those that scored six or less to be at high risk of bias. Similarly, for the randomised trials, we used the Cochrane Collaboration's tool for assessing the risk of bias. ${ }^{35}$ This tool evaluates seven possible sources of bias: random sequence generation, allocation concealment, blinding of participants and personnel, blinding of outcome assessment, incomplete outcome data, selective reporting, and other bias. For each individual domain, we classified studies into low, unclear, and high risk of bias.

\section{Data synthesis and analysis}

To enable a consistent approach to meta-analysis and interpretation of findings in this review, we used previously described methods to transform relative risk estimates for association of circulating 25-hydroxyvitamin D and mortality outcomes, ${ }^{36}$ which were often differently reported by each observational cohort study (for example, per unit change, per one standard deviation change, or comparing fifths, quarters, thirds, and other groupings), to consistently correspond to comparison of the bottom versus the top third of the baseline distribution of 25-hydroxyvitamin D concentrations in each study. Briefly, we transformed log risk ratios by assuming a normal distribution, with the comparison between extreme thirds being equivalent to 2.18 times the log risk ratio for one standard deviation increase (or equivalently as 2.18/2.54 times the log risk ratio for a comparison of extreme quarters). We calculated standard errors of the log risk ratios by using published confidence limits and standardised them in the same way. We assumed hazard ratios and odds ratios to approximate the same measure of risk ratios. We combined study specific risk ratios by using a random effects model that included between study heterogeneity (and additionally using fixed effect models). Where studies reported risk ratios with varying degrees of adjustments, we used the maximally adjusted estimate. We based subsidiary assessments involving circulating 25-hydroxyvitamin D cut-offs (defined as 21-29, 10-20, and $<10 \mathrm{ng} / \mathrm{mL})^{2} 3738$ compared with the reference category $(\geq 30$ $\mathrm{ng} / \mathrm{mL}$ ) on combining comparable risk ratio estimates across studies, using random effects meta-analyses (and additionally using fixed effect models). ${ }^{39} 40$

For randomised intervention trials we used reported adjusted risk ratios, or calculated study specific unadjusted risk ratios based on event rates if these were unavailable, for overall vitamin D supplementation (and individually by supplements of vitamins $\mathrm{D}_{3}$ and $\mathrm{D}_{2}$ subtypes). We calculated summary risk ratios by pooling the study specific estimates with a random effects model that included between study heterogeneity (parallel analyses used fixed effect models). We assessed consistency of findings across studies with standard $\chi^{2}$ tests and the $\mathrm{I}^{2}$ statistic. ${ }^{41}$ We used random effects meta-regression to quantify heterogeneity by comparing results from studies grouped according to study level characteristics. Additionally, we did univariate meta-regression analyses to investigate the effect of study level characteristics such as daily intervention dose of supplement and duration of intervention or follow-up on the size of the effect estimates for both supplementation trials and observational cohort studies. We used the natural logarithm of the risk ratio as the dependent variable and the study level characteristic as the explanatory factor. We assessed evidence of publication bias by using funnel plots and the Egger test. ${ }^{42}$ We calculated the population attributable risk with the following equation: $\mathrm{PAR} \%=100 \times \mathrm{Pe}(\mathrm{RR}-1) /(\mathrm{Pe}(\mathrm{RR}-1)+1),{ }^{43}$ where $\mathrm{Pe}$ is the prevalence of the exposure (eAppendix 5). All statistical tests were two sided and used a significance level of $\mathrm{P}<0.05$. We used Stata release-12 for all statistical analyses.

\section{Results}

The search strategy identified 2704 unique citations. After initial screening based on titles and abstracts, 320 articles remained for further evaluation. Of these articles, 225 were excluded in the subsequent detailed assessments for reasons shown in eFigure 1. The remaining 95 unique study reports met our inclusion criteria and were included in the meta-analysis (eAppendix 6). In aggregate, these included studies comprised 880128 unique participants and 71625 mortality outcomes (including 10777 deaths from cardiovascular disease and 6911 deaths from cancer) (table $\Downarrow$; eTables 1-3).

\section{Association of circulating 25-hydroxyvitamin D concentration with cause specific mortality}

Circulating 25-hydroxyvitamin D concentration in relation to subsequent risk of death was reported in 73 observational cohort studies, involving 849412 participants and 66511 mortality events recorded during an average follow-up ranging from 0.3 to 29 years (table $\downarrow$; eTable 1 ). Of these observational cohort studies, 38 involved participants from Europe, 26 from North America, 8 from the Asia-Pacific region, and 1 from South America. The median age of all included participants was 63 (interquartile range 59-71) years. We judged eight studies to be at low risk of bias, 41 to be at medium risk, and 24 studies to be at high risk of bias (eTable 1). Of the medium quality studies, all showed a potential bias in the selection of participants. The median baseline concentration of 25-hydroxyvitamin D in these studies was 20.7 (interquartile range 17.5-24.3) ng/mL. For the primary prevention cohorts, pooled risk ratios in comparisons of people in the bottom versus top thirds of the population distribution of baseline circulating 25-hydroxyvitamin D concentration, adjusted for several potential risk factors, were 1.35 (95\% confidence interval 1.13 to 1.61$)$ for death from cardiovascular disease (6416 events), 1.14 (1.01 to 1.29) for death from cancer (5003 events), 1.30 (1.07 to 1.59) for other non-vascular, non-cancer death (1444 events), and 1.35 (1.22 to 1.49 ) for all cause mortality (48 488 events) (fig $1 \Downarrow$ and eFigure 2). The corresponding pooled risk ratios were broadly similar in the secondary prevention cohorts. Additional analyses by various cut-off values of circulating 25 -hydroxyvitamin D concentration showed a significant inverse association with all cause mortality $(\mathrm{P}<0.05$; fig $2 \Downarrow)$. Assuming linearity, each 10 $\mathrm{ng} / \mathrm{mL}$ decline of 25-hydroxyvitamin D concentration was associated with a $16 \%$ (95\% confidence interval $8 \%$ to $23 \%$ ) increased risk of all cause mortality (fig $2 \Downarrow$ ).

In subsidiary analyses, we found significant inverse associations for various cause specific mortality outcomes, including deaths due to coronary disease, lymphoma, upper digestive tract cancer, and respiratory diseases (eFigure 3 ). We observed a moderate level of heterogeneity in observational studies, which was only partially explained by between study differences in various subgroups (figures $3 \Downarrow, 4 \Downarrow$, and $5 \Downarrow$ ). Specifically, the risk of all mortality outcomes for low baseline circulating

25-hydroxyvitamin D concentration was significantly higher in studies in which less than $10 \%$ of the population used vitamin D supplements (P for meta-regression<0.05; figures $3 \Downarrow, 4 \Downarrow$, and $5 \Downarrow)$. Additionally, risk of all cause mortality in participants with low 25-hydroxyvitamin D concentrations was significantly higher in studies with less than five years' average follow-up (P for meta-regression=0.001; fig $5 \Downarrow$ ). The overall associations observed, however, were similar across other subgroups such 
as latitude of study location, sex, study quality, levels of multivariate adjustment, assay methods, adjustments for seasonality or socioeconomic status, and geographical location (figures $3 \Downarrow, 4 \Downarrow$, and $5 \Downarrow$ and eFigure 4 ). Results from subsidiary univariate meta-regression analyses showed no evidence of associations of the duration of follow-up with risk of death from cardiovascular disease, death from cancer, other non-vascular, non-cancer death, and all cause mortality $(\mathrm{P}>0.05$ for all) (eFigure 5).

\section{Effects of vitamin D supplementation on all cause mortality}

Twenty two randomised controlled trials reported effects of vitamin D supplementation in isolation on mortality outcomes, including a total of 30716 participants in the supplement and control groups combined (table $\Downarrow$; eTable 3 ). Fourteen of these trials assessed the effect of vitamin $\mathrm{D}_{3}$, and eight reported effects of vitamin $\mathrm{D}_{2}$. Thirteen trials involved participants from Europe, five from North America, and four from the Asia-Pacific region. The average age of participants included in these trials ranged from 56 to 85 years. Eleven trials included participants from community based registers (six from the general population and five from care or residential homes), and the rest recruited participants from clinical registers. The risk of bias assessment in each trial is reported in eAppendix 4. Most of the trials had a low risk of bias for random sequence generation, allocation concealment, participants' blinding, and selective reporting. Seven trials had a high risk of bias for blinding of outcome assessment, and eight had a high bias in outcome data completion. Among the vitamin $\mathrm{D}_{3}$ studies, participants in the intervention arm received vitamin $\mathrm{D}_{3}$ supplementation ranging from 10 to $6000 \mathrm{IU} / \mathrm{day}$, and oral tablets were the principle form of supplementation. The corresponding range was 208 to 4500 IU/day for vitamin $\mathrm{D}_{2}$. After an average follow-up ranging from 0.38 to 6.8 years, a total of 2527 all cause mortality events occurred among participants in the intervention group compared with 2587 events in the control group, with a combined risk ratio of 0.98 ( 0.94 to 1.02$)$ in all studies. The corresponding risk ratios according to type of vitamin D supplementation was 0.89 (0.80 to 0.99$)$ for vitamin $\mathrm{D}_{3}$ and 1.04 (0.97 to 1.11 ) for vitamin $\mathrm{D}_{2}$ (fig $6 \Downarrow$ ).

We found no evidence of heterogeneity across vitamin $D_{3}$ (eFigure $6 \mathrm{a}$; $\mathrm{P}$ for heterogeneity $=0.34$ ) or vitamin $\mathrm{D}_{2}$ trials (eFigure 6b; $\mathrm{P}$ for heterogeneity $=0.38$ ). For vitamin $\mathrm{D}_{3}$, the overall effect did not vary significantly across location, sex, population source, daily dose, and duration of intervention or follow-up ( $\mathrm{P}$ for metaregression $>0.05$; fig $7 \Downarrow$ ). The effects, however, differed importantly for vitamin $\mathrm{D}_{2}$ supplementation, for which we observed an increased risk of mortality in the randomised controlled trials that used an intervention dose of 600 to $2000 \mathrm{IU} /$ day, had shorter average intervention period $(<1.5 v \geq 1.5$ years), and had high risk of bias ( $\mathrm{P}$ for metaregression $\leq 0.05$ for all; fig $7 \Downarrow$ ). Similarly, results from univariate meta-regression analysis showed no evidence of an association of daily intervention dose or average intervention period with treatment effect for vitamin $\mathrm{D}_{3}$ supplementation ( $\mathrm{P}=0.47$ and 0.50 , respectively). The evidence did, however, suggest associations of daily intervention dose and average intervention period with the treatment effect for vitamin $\mathrm{D}_{2}$ supplementation, although these were not statistically significant ( $\mathrm{P}=0.06$ and 0.07 , respectively) (eFigure 7). We had insufficient data to meaningfully combine the effects of vitamin D supplementation alone on cause specific mortality outcomes. We found no evidence of publication bias across all included studies in this review (P for Egger's asymmetry $>0.05$ for all) (eFigure 8).

\section{Prevalence of vitamin D deficiency and estimated absolute risk}

In supplementary analyses, based on data from available cohorts, the prevalence of vitamin D insufficiency (defined as 25 -hydroxyvitamin D concentration $<30 \mathrm{ng} / \mathrm{mL}$ ) was $69.5 \%$ (95\% confidence interval $62.1 \%$ to $77.7 \%$ ) for the United States and $86.4 \%$ (78.4\% to $95.2 \%$ ) for Europe. Furthermore, using 25-hydroxyvitamin D concentrations less than $10 \mathrm{ng} / \mathrm{mL}$ as the criterion, $4 \%$ and $15 \%$ of the general population were severely deficient in the Europe and United States, respectively (eFigure 9). Additionally, using the most recent mortality statistics for the United States and Europe ${ }^{44}{ }^{45}$ the estimated absolute risk differences for all cause mortality associated with vitamin D deficiency were 75.4 events in Europe and 96.6 events in the United States, per 100000 population, per year (eAppendix 5). Using the population prevalence estimates of vitamin D deficiency from this study, $9.4 \%$ of all deaths in Europe and $12.8 \%$ of those in the United States could be attributed to vitamin $\mathrm{D}$ deficiency.

\section{Discussion}

The findings of this review indicate that a moderate, but significant, inverse association exists between circulating vitamin D concentrations and the risk of all cause mortality in the primary prevention cohort studies. The inverse association was evident generally for all broad causes of death and more specifically for deaths due to coronary disease, lymphoma, upper digestive cancer, and respiratory disorders. In all randomised controlled trials combined, vitamin D supplementation, when given alone, did not reduce overall mortality significantly among older adults. However, when stratified by type of supplementation, vitamin $\mathrm{D}_{3}$, given singly, reduced all cause mortality significantly by $11 \%$. By contrast, supplementation with vitamin $\mathrm{D}_{2}$ alone had no overall effect on mortality.

\section{Possible explanations for findings}

The inverse association between vitamin $\mathrm{D}$ and mortality can be explained by several different mechanisms. Firstly, activated vitamin D may influence a range of biological responses involved in cellular growth, proliferation, and apoptosis and immune system functions. ${ }^{28}$ Vitamin D receptors and the enzyme required for its activation are present in most human cells and tissues, indicating a major role for vitamin D in "non-skeletal" physiological processes. Secondly, approximately 3000 binding sites for the vitamin D receptor have been found throughout the human genome,${ }^{46}$ indicating regulation of a very large number of genes (estimated to be about $3 \%$ of the human genome $^{2}$ ) either directly or indirectly responsive to vitamin $\mathrm{D}$ receptors. This, along with the potential adverse consequences of low 25-hydroxyvitamin D concentrations, such as coronary heart disease, cancer, and death, ${ }^{47}$ found in people with 25-hydroxyvitamin D related genetic variants, reinforces the importance of an endocrine system beyond extracellular calcium and phosphate homeostasis. ${ }^{46}$ Thirdly, the positive association between vitamin $\mathrm{D}$ concentrations and longer leucocyte telomere length, a potential determinant of age related disorders and overall longevity, ${ }^{48}$ emphasises the possible beneficial effects of vitamin D on healthy ageing and associated outcomes. Fourthly, as primary causes of vitamin D deficiency include insufficient exposure to sunlight, poor diet, increased adiposity, and reduced synthesis or absorption, ${ }^{49}$ a poor vitamin D status 
might essentially reflect suboptimal lifestyle and socioeconomic circumstances. These individual level factors may, in turn, influence risk for their potential roles on several established determinants of morbidity and mortality such as smoking, blood pressure, body mass index, and use of supplements. ${ }^{50}$ Although most of the studies included in this review controlled for these characteristics, and our pooled estimates were largely unchanged when they were further stratified by adjustment for standard socioeconomic factors, potential residual and unmeasured confounding by differences in diet, lifestyle, and socioeconomic status remains a concern. Such unaccounted confounding could partly explain the discrepancy of findings observed earlier between observational and interventional studies of other dietary factors. ${ }^{51}$ Finally, our study indicates that vitamin D is inversely and moderately associated with risk of death from coronary disease, lymphoma, cancers of the upper digestive tract, and respiratory disease. Although these associations require better characterisation in future larger studies, local expression of vitamin D receptors and systemic immunomodulatory roles of vitamin $\mathrm{D}$ have been proposed to explain them..$^{52-55}$

Subgroup analyses among observational studies indicated that the inverse associations of circulating 25-hydroxyvitamin D concentration with all cause and cancer specific mortality were significantly stronger in the populations with a low prevalence of vitamin D supplement use. This suggests that the effect of vitamin D may be dependent on baseline vitamin D status. Given that baseline circulating 25-hydroxyvitamin D concentrations in a population with low prevalent vitamin D supplement use is likely to be low, ${ }^{56}$ and that the risk of mortality outcomes is known to be greater at the lower concentrations of 25 -hydroxyvitamin $\mathrm{D},{ }^{27}$ these findings are not unexpected. In addition, a previous study has suggested a threshold effect in 25-hydroxyvitamin D concentrations up to $112 \mathrm{nmol} / \mathrm{L}$, which can be achieved by daily use of 600 IU of vitamin $\mathrm{D}_{3}{ }^{57}$ Additionally, we found a significantly higher mortality risk of low 25-hydroxyvitamin D concentrations in studies with a follow-up of less than five years. This may be attributed to reverse causality, in which people have underlying diseases that are associated with low 25-hydroxyvitamin D concentrations, such as cardiometabolic diseases.

Our meta-analysis of all available randomised controlled trials of vitamin D supplements, given singly among principally older adults, suggests that this nutrient may not significantly reduce mortality outcomes. However, when we considered the effects of specific vitamin D metabolites, supplementation in the form of vitamin $\mathrm{D}_{3}$ (animal derived, known as cholecalciferol) but not vitamin $\mathrm{D}_{2}$ (plant based, known as ergocalciferol) was associated with reduced mortality. Earlier evidence described ergocalciferol as being potentially less potent, unit for unit, in maintaining 25-hydroxyvitamin D concentrations in the circulation, ${ }^{58}$ so the expected effect of vitamin $\mathrm{D}_{3}$ on mortality could be greater. Additionally, previous reviews reported that in the absence of concomitant use of calcium supplements, compared with vitamin $\mathrm{D}_{3}$, vitamin $\mathrm{D}_{2}$ was associated with a significantly lower overall increase in serum 25-hydroxyvitamin D concentration. ${ }^{59}{ }^{60}$ Interestingly, concomitant use of vitamin $\mathrm{D}$ with calcium at baseline was associated with lower increases in 25-hydroxyvitamin D concentrations. ${ }^{59}$ Subgroup analyses showed that vitamin $\mathrm{D}_{2}$ supplementation increased the aggregate risk of mortality in trials that had shorter average intervention periods. Similar higher risks were reported for trials using lower intervention doses. The discrepant findings in our meta-analysis could also be explained by insufficient power (average follow-up duration in the vitamin $\mathrm{D}_{2}$ trials was about a year less than for $\mathrm{D}_{3}$ trials) or, importantly, factors other than supplements themselves in these studies (such as diversity in population characteristics); therefore, further randomised controlled trials are needed to reinforce these findings.

\section{Comparison with previous work}

Findings of this updated meta-analysis generally concur with and further extend the previous reviews in several important ways. Firstly, this study had enhanced power to examine the associations in greater detail. For example, our meta-analysis of the primary prevention cohort studies involved about 10 times as many participants and three times as many mortality outcomes as previous reviews on this topic combined, ${ }^{10} 1920$ and included about 10 recent, large scale observational cohort studies. Secondly, in contrast to the earlier reviews, we have done a systematic synthesis of all available primary and secondary prevention cohorts to quantify the risk of both composite and various cause specific death outcomes in a single comprehensive investigation. Thirdly, we have analysed and presented standardised pooled risk estimates comparing extreme thirds of baseline distribution of vitamin $\mathrm{D}$, and by pre-specified vitamin D cut-offs. Fourthly, unlike previous reviews that included all randomised studies with mixed interventions, ${ }^{18}{ }^{21}$ our most up to date meta-analysis of randomised controlled trials included exclusively the studies that administered vitamin D alone. Finally, we did detailed analyses under a broader range of individual and study level circumstances to explore the potential sources of heterogeneity. Nevertheless, the findings from our trial component are consistent with the earlier meta-analysis (based on randomised controlled trials irrespective of concomitant supplementation with calcium) that also reported heterogeneity in efficacy between the two forms of supplement. ${ }^{18}$

\section{Implications of findings}

Our findings may have several implications. They underscore a potentially deleterious role of low vitamin $\mathrm{D}$ in all cause and cause specific mortality in both primary and secondary prevention cohorts. Additionally, a beneficial effect was observed for supplementation with vitamin $\mathrm{D}_{3}$ in the randomised controlled trials. This is of significant public health importance, as the gradual decline in circulating 25-hydroxyvitamin D concentrations reported globally is likely to continue owing to the increase in the proportion of older populations, obesity, and lack of adequate sun exposure combined with sunscreen use. ${ }^{61}$ Our review further highlights existing scientific gaps in the trial evidence and, therefore, stimulates future research. ${ }^{62}$ For instance, available intervention studies were generally insufficiently powered to reliably assess the optimum dosage, not able to examine potential toxic effects over prolonged use, and unable to reliably assess the efficacy in low risk general populations as most of the included community based studies involved solely older participants. Finally, compared with other conventional risk factors of ill health, the estimated population attributable risk of death due to suboptimal vitamin D in our study seems to be substantial. For example, in the United States, we estimated the population attributable risk due to vitamin D deficiency to be about $13 \%$. The corresponding estimates in the United States were about $20 \%$ for smoking, ${ }^{63}$ about $11 \%$ for physical inactivity, ${ }^{64}$ and about $9 \%$ for alcohol consumption. ${ }^{65}$. This reinforces the potential importance of scalable, cost effective public health strategies (such as moderate sun exposure, supplementation, and food fortification) in improving the overall vitamin D status to reduce premature deaths worldwide. 


\section{Strengths and limitations of study}

The generalisability of our findings has been enhanced by the involvement of data from almost 900000 participants in 26 nations. We used standardised estimates to allow consistent comparisons and examined a wide range of characteristics. However, the review was limited by the moderate amount of available data on several cause specific mortality outcomes. For example, even in aggregate, fewer than 1000 site specific cancer deaths were generally recorded in the observational cohort studies. Observational data also provide limited clarity on whether observed associations with mortality outcomes are direct (that is, due to suboptimal vitamin D) or indirect (due to shared determinants such as obesity, body composition, or social status). Furthermore, as all included observational studies lacked serial assessment of circulating 25-hydroxyvitamin D concentration in the same individuals, reliable assessment of the extent of any within person variability in circulating 25-hydroxyvitamin D concentration was not possible. Because most characteristics of epidemiological studies are measured with a degree of error and are subject to fluctuations within individuals over time, correction of such variability in future studies would help to avoid "regression dilution." ${ }^{667}$ Although the observational studies are unable to assess the causal association, evidence from the intervention studies could provide concluding evidence in this respect. However, such trials are generally sparse, include chiefly older people (that is, a population with a high competing risk of death due to comorbidities $^{68}$ ), and do not typically present data on cause specific deaths as the primary outcomes of interest. Furthermore, although most of the trials included in this review seem to have a low risk of bias, our findings should be interpreted with some caution, owing to the relatively small number of trials for each intervention subtype, especially for primary prevention. Therefore, our findings intensify the need for detailed future intervention studies that involve free living general populations, quantify efficacy in important subgroups such as non-white ethnicities, are adequately powered and sufficiently prolonged to help judge appropriate dosage and safety, aim to ascertain a broader range of fatal and non-fatal outcomes than has been customary in the randomised controlled trials thus far, and study both vitamin $D_{2}$ and $D_{3}$ to identify which form of vitamin $D$ supplementation can be most efficient and safe.

\section{Conclusions}

Evidence from observational studies indicates inverse associations of circulating 25-hydroxyvitamin D concentration with risks of death from cardiovascular disease, death from cancer, and non-vascular, non-cancer death. Supplementation with vitamin $\mathrm{D}_{3}$ reduced overall mortality significantly among older adults; however, before any widespread supplementation, further studies will be required to determine the optimal dose and duration and to reliably establish whether vitamin $\mathrm{D}_{3}$ affects the mortality risk differently than vitamin $\mathrm{D}_{2}$.

We thank the following study investigators for helping us with tabular information on vitamin D: Lily Lui, Warren Browner, Joe Ix, Tobias Larsson, Johan Sundstrom, Winfried Marz, Marcus Kleber, Jukka Marniemi, Natasha Wiebe, CARE Study Investigators, Peter Willeit, Francesca Tentori, and Kamyar Kalantar-Zadeh.

Contributors: SK, AV, CO-W, SC, and JCK-deJ contributed equally to this work. RC and OHF conceived the study. SK and RC did the analyses. RC, SK, CO-W, SC, and HK searched the literature and extracted the data. RC and OHF wrote the manuscript. JCK-deJ, SK, $\mathrm{AV}, \mathrm{CPB}, \mathrm{DP}, \mathrm{MBH}, \mathrm{BSF}, \mathrm{AP}, \mathrm{LJ}, \mathrm{FC}, \mathrm{FBH}$, and OHF contributed to the initial revision of the manuscript. LJ contributed to the critical revision of the manuscript before publication. OHF is the guarantor.

Funding: None. AV, JCK-deJ, and OHF work in ErasmusAGE, a centre for aging research across the life course funded by Nestlé Nutrition (Nestec Ltd), Metagenics Inc, and AXA. Nestlé Nutrition (Nestec Ltd), Metagenics Inc, and AXA had no role in design and conduct of the study; collection, management, analysis, and interpretation of the data; or preparation, review, or approval of the manuscript.

Competing interests: All authors have completed the ICMJE uniform disclosure form at www.icmje.org/coi_disclosure.pdf (available on request from the corresponding authors) and declare: no support from any organisation for the submitted work; no financial relationships with any organisations that might have an interest in the submitted work in the previous three years; no other relationships or activities that could appear to have influenced the submitted work.

Ethical approval: Not needed.

Transparency declaration: The lead author (the manuscript's guarantor) affirms that the manuscript is an honest, accurate, and transparent account of the study being reported; that no important aspects of the study have been omitted; and that any discrepancies from the study as planned have been explained.

Data sharing: No additional data available.

1 Holick MF. Vitamin D: physiology, dietary sources and requirements. In: Encyclopedia of human nutrition. 2nd ed. Academic Press, 2005.

2 Holick MF. Vitamin D deficiency. N Engl J Med 2007;357:266-81.

3 Bischoff-Ferrari HA, Willett WC, Orav EJ, Lips P, Meunier PJ, Lyons RA, et al. A pooled analysis of vitamin $D$ dose requirements for fracture prevention. $N$ Engl $J$ Med 2012;367:40-9.

4 Bischoff-Ferrari HA, Dawson-Hughes B, Willett WC, Staehelin HB, Bazemore MG, Zee RY, et al. Effect of vitamin D on falls: a meta-analysis. JAMA 2004;291:1999-2006.

5 Winzenberg TM, Powell S, Shaw KA, Jones G. Vitamin D supplementation for improving bone mineral density in children. Cochrane Database Syst Rev 2010;(10):CD006944.

6 Reid IR, Bolland MJ, Grey A. Effects of vitamin D supplements on bone mineral density: a systematic review and meta-analysis. Lancet 2014;383:146-55.

7 Munger KL, Levin LI, Hollis BW, Howard NS, Ascherio A. Serum 25-hydroxyvitamin D levels and risk of multiple sclerosis. JAMA 2006;296:2832-8.

8 Arnson $\mathrm{Y}$, Amital $\mathrm{H}$, Shoenfeld $\mathrm{Y}$. Vitamin $\mathrm{D}$ and autoimmunity: new aetiological and therapeutic considerations. Ann Rheum Dis 2007;66:1137-42.

9 Sabetta JR, DePetrillo P, Cipriani RJ, Smardin J, Burns LA, Landry ML. Serum 25-hydroxyvitamin $D$ and the incidence of acute viral respiratory tract infections in healthy adults. PLoS One 2010;5:e11088.

10 Brondum-Jacobsen P, Benn M, Jensen GB, Nordestgaard BG. 25-hydroxyvitamin D levels and risk of ischemic heart disease, myocardial infarction, and early death: population-based study and meta-analyses of 18 and 17 studies. Arterioscler Thromb Vasc Biol 2012;32:2794-802.

11 Khan H, Kunutsor S, Franco OH, Chowdhury R. Vitamin D, type 2 diabetes and other metabolic outcomes: a systematic review and meta-analysis of prospective studies. Proc Nutr Soc 2013;72:89-97.

12 Gandini S, Boniol M, Haukka J, Byrnes G, Cox B, Sneyd MJ, et al. Meta-analysis of observational studies of serum 25-hydroxyvitamin $D$ levels and colorectal, breast and prostate cancer and colorectal adenoma. Int J Cancer 2011;128:1414-24.

13 Institute of Medicine. Dietary reference intakes for calcium and vitamin D. National Academies Press, 2011.

14 Liu PT, Stenger S, Li H, Wenzel L, Tan BH, Krutzik SR, et al. Toll-like receptor triggering of a vitamin D-mediated human antimicrobial response. Science 2006;311:1770-3.

15 Mahon BD, Gordon SA, Cruz J, Cosman F, Cantorna MT. Cytokine profile in patients with multiple sclerosis following vitamin D supplementation. J Neuroimmunol 2003;134:128-32.

16 Melamed ML, Michos ED, Post W, Astor B. 25-hydroxyvitamin D levels and the risk of mortality in the general population. Arch Intern Med 2008;168:1629-37.

17 Zittermann A, Schleithoff SS, Frisch S, Götting C, Kuhn J, Koertke H, et al. Circulating calcitriol concentrations and total mortality. Clin Chem 2009;55:1163-70.

18 Bjelakovic G, Gluud LL, Nikolova D, Whitfield K, Wetterslev J, Simonetti RG, et al. Vitamin D supplementation for prevention of mortality in adults. Cochrane Database Syst Rev 2011;(7):CD007470.

19 Zittermann A, lodice S, Pilz S, Grant WB, Bagnardi V, Gandini S. Vitamin D deficiency and mortality risk in the general population: a meta-analysis of prospective cohort studies. Am J Clin Nutr 2012;95:91-100.

20 Pilz S, lodice S, Zittermann A, Grant WB, Gandini S. Vitamin D status and mortality risk in CKD: a meta-analysis of prospective studies. Am J Kidney Dis 2011;58:374-82.

21 Autier P, Gandini S. Vitamin D supplementation and total mortality: a meta-analysis of randomized controlled trials. Arch Intern Med 2007;167:1730-7.

22 Bolland MJ, Grey A, Avenell A, Gamble GD, Reid IR. Calcium supplements with or without vitamin $D$ and risk of cardiovascular events: reanalysis of the Women's Health Initiative limited access dataset and meta-analysis. BMJ 2011;342:d2040.

23 Moher D, Liberati A, Tetzlaff J, Altman DG. Preferred reporting items for systematic reviews and meta-analyses: the PRISMA statement. PLoS Med 2009;6:e1000097.

24 Stroup DF, Berlin JA, Morton SC, Olkin I, Williamson GD, Rennie D, et al. Meta-analysis of observational studies in epidemiology: a proposal for reporting. JAMA 2000;283:2008-12.

25 Meyer F, Liu G, Douville P, Samson E, Xu W, Adjei A, et al. Dietary vitamin D intake and serum 25 -hydroxyvitamin $D$ level in relation to disease outcomes in head and neck cancer patients. Int J Cancer 2011;128:1741-6. 


\section{What is already known on this topic}

Vitamin $\mathrm{D}$ may be associated with many extraskeletal disease conditions, including overall mortality outcomes

However, associations of vitamin $\mathrm{D}$ concentrations with risk of death from a broad range of causes, under different circumstances, and across primary and secondary prevention settings, remain less well understood

\section{What this study adds}

Updated meta-analyses of observational studies indicate inverse associations of circulating vitamin $\mathrm{D}$ concentrations with risks of deaths from cardiovascular disease, cancer, and other causes

Combined data from all relevant randomised intervention studies show that, when given alone, vitamin $D$ supplementation may not reduce overall mortality significantly among older adults

When data were stratified by type of supplementation, vitamin $\mathrm{D}_{3}$, given singly, reduced mortality significantly by $11 \%$

By contrast, supplementation with vitamin $\mathrm{D}_{2}$ alone had no overall effect on mortality

26 Mezawa H, Sugiura T, Watanabe M, Norizoe C, Takahashi D, Shimojima A, et al. Serum vitamin $D$ levels and survival of patients with colorectal cancer: post-hoc analysis of a prospective cohort study. BMC Cancer 2010;10:347.

27 Michaëlsson K, Baron JA, Snellman G, Gedeborg R, Byberg L, Sundström J, et al. Plasma vitamin $\mathrm{D}$ and mortality in older men: a community-based prospective cohort study. Am $J$ Clin Nutr 2010;92:841-8.

28 Tomson J, Emberson J, Hill M, Gordon A, Armitage J, Shipley M, et al. Vitamin D and risk of death from vascular and non-vascular causes in the Whitehall study and meta-analyses of 12000 deaths. Eur Heart $J$ 2013;34:1365-74.

29 Avenell A, MacLennan GS, Jenkinson DJ, McPherson GC, McDonald AM, Pant PR, et al. Long-term follow-up for mortality and cancer in a randomized placebo-controlled tria of vitamin D(3) and/or calcium (RECORD trial). J Clin Endocrinol Metab 2012;97:614-22.

30 Trivedi DP, Doll R, Khaw KT. Effect of four monthly oral vitamin D3 (cholecalciferol) supplementation on fractures and mortality in men and women living in the community: randomised double blind controlled trial. BMJ 2003;326:469.

31 Punthakee Z, Bosch J, Dagenais G, Diaz R, Holman R, Probstfield J, et al. Design, history and results of the Thiazolidinedione Intervention with vitamin D Evaluation (TIDE) randomised controlled trial. Diabetologia 2012;55:36-45.

32 Skaaby T, Husemoen LL, Pisinger C, Jørgensen T, Thuesen BH, Pisinger C, et al. Vitamin D status and incident cardiovascular disease and all-cause mortality: a general population study. Endocrine 2013; published online 23 Nov.

33 Kritchevsky SB, Tooze JA, Neiberg RH, Schwartz GG, Hausman DB, Johnson MA, et al. 25 -Hydroxyvitamin $D$, parathyroid hormone, and mortality in black and white older adults: the health ABC study. J Clin Endocrinol Metab 2012;97:4156-65.

34 Wells GA, Shea B, O'Connell D, J Peterson, V Welch, M Losos, et al. The Newcastle-Ottawa Scale (NOS) for assessing the quality of nonrandomised studies in meta-analyses. 2011. www.ohri.ca/programs/clinical_epidemiology/oxford.asp.

35 Higgins JP, Altman DG, Gøtzsche PC, Jüni P, Moher D, Oxman AD, et al. The Cochrane Collaboration's tool for assessing risk of bias in randomised trials. BMJ 2011;343:d5928.

36 Danesh J, Collins R, Appleby P, Peto R. Association of fibrinogen, C-reactive protein, albumin, or leukocyte count with coronary heart disease: meta-analyses of prospective studies. JAMA 1998:279:1477-82.

37 Lee JH, O'Keefe JH, Bell D, Hensrud DD, Holick MF. Vitamin D deficiency an important common, and easily treatable cardiovascular risk factor? J Am Coll Cardiol 2008;52:1949-56

38 Ginde AA, Liu MC, Camargo CA Jr. Demographic differences and trends of vitamin D insufficiency in the US population, 1988-2004. Arch Intern Med 2009;169:626-32.

39 Larsson SC, Orsini N. Fish consumption and the risk of stroke: a dose-response meta-analysis. Stroke 2011;42:3621-3.

40 He K, Song Y, Daviglus ML, Liu K, Van Horn L, Dyer AR, et al. Fish consumption and incidence of stroke: a meta-analysis of cohort studies. Stroke 2004;35:1538-42.

41 Higgins JP, Thompson SG, Deeks JJ, Altman DG. Measuring inconsistency in meta-analyses. BMJ 2003;327:557-60.

42 Egger M, Davey Smith G, Schneider M, Minder C. Bias in meta-analysis detected by a simple, graphical test. BMJ 1997;315:629-34.

43 Rothman K, Greenland S. Modern epidemiology. 2nd ed. Lippincott Williams and Wilkins, 1998.

44 World Health Organization. Global Health Observatory: Country statistics. www.who.int gho/countries/en/.

45 European Commission. Eurostat: causes of death statistics. 2012. http://epp.eurostat.ec. europa.eu/statistics_explained/index.php/Causes of death statistics.

46 Ramagopalan SV, Heger A, Berlanga AJ, Maugeri NJ, Lincoln MR, Burrell A, et al. A ChIP-seq defined genome-wide map of vitamin $D$ receptor binding: associations with disease and evolution. Genome Res 2010;20:1352-60.

47 Levin GP, Robinson-Cohen C, de Boer IH, Houston DK, Lohman K, Liu Y, et al. Genetic variants and associations of 25-hydroxyvitamin $\mathrm{D}$ concentrations with major clinical outcomes. JAMA 2012;308:1898-905.

48 Richards JB, Valdes AM, Gardner JP, Paximadas D, Kimura M, Nessa A, et al. Higher serum vitamin $D$ concentrations are associated with longer leukocyte telomere length in women. Am J Clin Nutr 2007;86:1420-5.

49 Lips P. Vitamin D status and nutrition in Europe and Asia. J Steroid Biochem Mol Biol 2007:103:620-5.
50 Bolland MJ, Grey A, Avenell A, Gamble GD, Reid IR. Calcium supplements with or without vitamin $D$ and risk of cardiovascular events: reanalysis of the Women's Health Initiative limited access dataset and meta-analysis. BMJ 2011;19:342.

51 Ye Z, Song H. Antioxidant vitamins intake and the risk of coronary heart disease: meta-analysis of cohort studies. Eur J Cardiovasc Prev Rehabil 2008;15:26-34.

52 Renne C, Benz AH, Hansmann ML. Vitamin D3 receptor is highly expressed in Hodgkin's lymphoma. BMC Cancer 2012;12:215.

53 Somjen D, Weisman Y, Kohen F, Gayer B, Limor R, Sharon O, et al. 25-hydroxyvitamin D3-1alpha-hydroxylase is expressed in human vascular smooth muscle cells and is upregulated by parathyroid hormone and estrogenic compounds. Circulation 2005;111:1666-71.

54 Herr C, Greulich T, Koczulla RA, Meyer S, Zakharkina T, Branscheidt M, et al. The role of vitamin $\mathrm{D}$ in pulmonary disease: COPD, asthma, infection, and cancer. Respir Res 2011:12:31.

55 Trowbridge R, Mittal SK, Agrawal DK. Vitamin D and the epidemiology of upper gastrointestinal cancers: a critical analysis of the current evidence. Cancer Epidemiol Biomarkers Prev 2013;22:1007-14

56 Dror Y, Giveon S, Hoshen M, Feldhamer I, Balicer R, Feldman B. Vitamin D levels for preventing acute coronary syndrome and mortality: evidence of a non-linear association. $J$ Clin Endocrinol Metab 2013;98(5):2160-7.

57 Gallagher JC, Sai A, Templin T 2nd, Smith L. Dose response to vitamin D supplementation in postmenopausal women: a randomized trial. Ann Intern Med 2012;156:425-37.

58 Armas LA, Hollis BW, Heaney RP. Vitamin D2 is much less effective than vitamin D3 in humans. J Clin Endocrinol Metab 2004;89:5387-91.

59 Autier P, Gandini S, Mullie P. A systematic review: influence of vitamin D supplementation on serum 25-hydroxyvitamin D concentration. J Clin Endocrinol Metab 2012:97:2606-13.

60 Tripkovic L, Lambert H, Hart K, Smith CP, Bucca G, Penson S, et al. Comparison of vitamin D2 and vitamin D3 supplementation in raising serum 25 -hydroxyvitamin $D$ status: a systematic review and meta-analysis. Am J Clin Nutr 2012;95:1357-64.

61 Holick MF, Chen TC. Vitamin D deficiency: a worldwide problem with health consequences. Am J Clin Nutr 2008;87:1080-6S.

62 Ross AC, Manson JE, Abrams SA, Aloia JF, Brannon PM, Clinton SK, et al. The 2011 report on dietary reference intakes for calcium and vitamin $D$ from the Institute of Medicine: what clinicians need to know. J Clin Endocrinol Metab 2011;96:53-8.

63 Fenelon A, Preston SH. Estimating smoking-attributable mortality in the United States. University of Pennsylvania, 2011 (PSC Working Paper Series, PSC 11-02).

64 Lee IM, Shiroma EJ, Lobelo F, Puska P, Blair SN, Katzmarzyk PT, et al. Effect of physical inactivity on major non-communicable diseases worldwide: an analysis of burden of disease and life expectancy. Lancet 2012;380:219-29.

65 Shield KD, Gmel G, Kehoe-Chan T, Dawson DA, Grant BF, Rehm J. Mortality and potential years of life lost attributable to alcohol consumption by race and sex in the United States in 2005. PLoS One 2013;8:e51923.

66 Clarke R, Shipley M, Lewington S, Youngman L, Collins R, Marmot M, et al. Underestimation of risk associations due to regression dilution in long-term follow-up of prospective studies. Am J Epidemiol 1999;150:341-53.

67 Fibrinogen Studies Collaboration, Wood AM, White I, Thompson SG, Lewington S, Danesh J. Regression dilution methods for meta-analysis: assessing long-term variability in plasma fibrinogen among 27,247 adults in 15 prospective studies. Int J Epidemiol 2006;35:1570-8.

68 Berry SD, Ngo L, Samelson EJ, Kiel DP. Competing risk of death: an important consideration in studies of older adults. J Am Geriatr Soc 2010;58:783-7.

Accepted: 27 February 2014

\section{Cite this as: BMJ 2014;348:g1903}

This is an Open Access article distributed in accordance with the Creative Commons Attribution Non Commercial (CC BY-NC 3.0) license, which permits others to distribute, remix, adapt, build upon this work non-commercially, and license their derivative works on different terms, provided the original work is properly cited and the use is non-commercial. See: http://creativecommons.org/licenses/by-nc/3.0/. 


\section{Table}

\begin{tabular}{|c|c|c|}
\hline & Observational cohort studies & Intervention studies \\
\hline \multicolumn{3}{|l|}{ Eligible studies } \\
\hline No of unique studies & 73 & 22 \\
\hline Median (IQR) follow-up (years) & $6.0(3.0-9.5)$ & $1.4(0.5-3.0)$ \\
\hline \multicolumn{3}{|l|}{ Participants } \\
\hline Total No of participants & 849412 & 30716 \\
\hline Median (IQR) No of participants & $1073(510-2429)$ & $343(124-2578)$ \\
\hline Total No of deaths & 66511 & 5114 \\
\hline Median (IQR) No of deaths & $224(106-633)$ & $22.5(7-471)$ \\
\hline Median (IQR) \% male & $51(35-62)$ & - \\
\hline Median (IQR) age (years) & $63(59-71)$ & $77(56-85)$ \\
\hline \multicolumn{3}{|l|}{ Baseline population } \\
\hline Not selected on basis of prior chronic disease & $29(788282)$ & $9(24828)$ \\
\hline With pre-existing chronic disease & $44(61130)$ & $13(9195)$ \\
\hline \multicolumn{3}{|l|}{ Location } \\
\hline Europe & $38(330573)$ & $13(25789)$ \\
\hline North America & $26(90342)$ & $5(1939)$ \\
\hline Asia-Pacific & $8(427515)$ & $4(2988)$ \\
\hline South America & $1(982)$ & - \\
\hline \multicolumn{3}{|l|}{ Sample type } \\
\hline Serum & $57(822340)$ & - \\
\hline Plasma & $16(27072)$ & - \\
\hline \multicolumn{3}{|l|}{ Assay method } \\
\hline Radioimmunoassay & $34(61013)$ & - \\
\hline Automated immunoassays & $19(753285)$ & - \\
\hline Chromatographic methods & $20(35114)$ & - \\
\hline \multicolumn{3}{|l|}{ 25-hydroxyvitamin D concentration } \\
\hline Median (IQR) pooled concentration at baseline ( $\mathrm{ng} / \mathrm{mL})$ & $20.7(17.5-24.3)$ & $15.2(10.4-21.3)$ \\
\hline \multicolumn{3}{|l|}{ Outcome-No of studies (No of events) ${ }^{*}$} \\
\hline All cause mortality & $68(64636)$ & $22(5114)$ \\
\hline Cardiovascular mortality & $29(10203)$ & $3(574)$ \\
\hline Cancer mortality & $17(6620)$ & $2(291)$ \\
\hline Other non-vascular, non-cancer mortality & $10(2565)$ & - \\
\hline
\end{tabular}

$I Q R=$ interquartile range.

*Several studies provided data on multiple outcomes of interest. 


\section{Figures}

\begin{tabular}{|c|c|c|c|c|c|}
\hline & $\begin{array}{l}\text { No of } \\
\text { studies }\end{array}$ & $\begin{array}{c}\text { No of } \\
\text { participants }\end{array}$ & $\begin{array}{l}\text { No of } \\
\text { deaths }\end{array}$ & $\begin{array}{l}\text { Relative risk }(95 \% \mathrm{Cl}) * \text { for } \\
\text { cause specific mortality }\end{array}$ & $\begin{array}{l}\text { Relative risk }(95 \% \mathrm{Cl})^{*} \text { fo } \\
\text { cause specific mortality }\end{array}$ \\
\hline \multicolumn{6}{|l|}{ Cardiovascular death } \\
\hline Primary prevention cohorts & 19 & 80662 & 6416 & $\longrightarrow$ & $1.35(1.13$ to 1.61$)$ \\
\hline Secondary prevention cohorts & 510 & 20987 & 3787 & $\longrightarrow$ & $1.60(1.32$ to 1.94$)$ \\
\hline All cohorts & 29 & 101649 & 10203 & $\rightarrow$ & $1.43(1.25$ to 1.64$)$ \\
\hline \multicolumn{6}{|l|}{ Cancer death } \\
\hline Primary prevention cohorts & 12 & 104353 & 5003 & $\rightarrow-$ & $1.14(1.01$ to 1.29$)$ \\
\hline Secondary prevention cohorts & 5 & 16382 & 1617 & $\longrightarrow$ & 1.59 (1.17 to 2.16$)$ \\
\hline All cohorts & 17 & 120735 & 6620 & $\longrightarrow-$ & $1.25(1.10$ to 1.43$)$ \\
\hline \multicolumn{6}{|c|}{ Non-cardiovascular, non-cancer death } \\
\hline Primary prevention cohorts & 7 & 38526 & 1444 & $\longrightarrow$ & $1.30(1.07$ to 1.59$)$ \\
\hline Secondary prevention cohorts & 3 & 13035 & 1121 & $\longrightarrow$ & $1.49(0.94$ to 2.35$)$ \\
\hline All cohorts & 10 & 51561 & 2565 & $\longrightarrow$ & $1.34(1.13$ to 1.60$)$ \\
\hline \multicolumn{6}{|l|}{ All cause mortality } \\
\hline Primary prevention cohorts & 27 & 780990 & 48488 & $\rightarrow-$ & 1.35 (1.22 to 1.49$)$ \\
\hline Secondary prevention cohorts & 541 & 59918 & 16148 & $\rightarrow-$ & $1.50(1.36$ to 1.65$)$ \\
\hline \multirow[t]{2}{*}{ All cohorts } & 68 & 840908 & 64636 & $\rightarrow-$ & $1.44(1.34$ to 1.55$)$ \\
\hline & & & 0.5 & 1 & 2.5 \\
\hline
\end{tabular}

Fig 1 Association of circulating 25-hydroxyvitamin D concentrations with cause specific mortality in observational cohort studies. *Pooled estimates are based on random effects meta-analysis. Using fixed effects models, for primary prevention cohorts, secondary prevention cohorts, and all cohorts, the estimates were 1.40 (1.32 to 1.47), 1.50 (1.35 to 1.66), and 1.42 (1.35 to 1.49 ) for cardiovascular deaths; 1.10 (1.02 to 1.17$), 1.45$ (1.28 to 1.65$)$, and 1.16 (1.10 to 1.24$)$ for cancer deaths; 1.28 (1.12 to 1.47$), 1.38$ (1.09 to 1.75 ), and 1.30 (1.16 to 1.47) for non-vascular, non-cancer deaths; and 1.45 (1.41 to 1.49$), 1.49$ (1.42 to 1.56$)$, and 1.44 (1.40 to 1.47) for all cause deaths. Size of data marker is proportional to inverse of variance of relative risk; horizontal line represents $95 \% \mathrm{Cl}$. Corresponding forest plots and $\mathrm{I}^{2}(95 \% \mathrm{Cl})$ estimates are provided in supplementary material

\begin{tabular}{|c|c|c|c|c|c|}
\hline & $\begin{array}{l}\text { No of } \\
\text { studies }\end{array}$ & $\begin{array}{c}\text { No of } \\
\text { participants }\end{array}$ & $\begin{array}{c}\text { No of } \\
\text { deaths }\end{array}$ & $\begin{array}{c}\text { Relative risk } \\
(95 \% \mathrm{Cl})\end{array}$ & $\begin{array}{c}\text { Relative risk } \\
(95 \% \mathrm{Cl})\end{array}$ \\
\hline \multicolumn{6}{|c|}{ Pre-specified laboratory cut-offs $(\mathrm{ng} / \mathrm{mL})^{\star}$} \\
\hline $21-29 v \geq 30$ & 14 & 500732 & 27093 & \multirow[t]{2}{*}{$\rightarrow$} & 1.07 (1.01 to 1.15$)$ \\
\hline $10-20 v \geq 30$ & 12 & 457801 & 22997 & & $1.20(1.12$ to 1.27$)$ \\
\hline$<10 v \geq 30$ & 11 & 457262 & 23993 & $\longrightarrow$ & $1.50(1.21$ to 1.87$)$ \\
\hline \multicolumn{6}{|l|}{ Dose-response assessment } \\
\hline \multirow[t]{3}{*}{ Each $10 \mathrm{ng} / \mathrm{mL}$ decrease } & 18 & 480579 & 29345 & $\rightarrow$ & 1.16 (1.08 to 1.23$)$ \\
\hline & & & 0.75 & 1.251 .5 & 2 \\
\hline & & \multicolumn{4}{|c|}{$\begin{array}{l}\text { Relative risk }(95 \% \mathrm{Cl}) \\
\text { of all cause death }\end{array}$} \\
\hline
\end{tabular}

Fig 2 Association of circulating 25-hydroxyvitamin D concentrations with all cause mortality, based on primary prevention cohorts. *Indirect comparisons based on available studies with relevant information in each category; summary estimates presented were calculated using random effects models. Using fixed effects models, the estimates were 1.09 (1.06 to 1.11) for clinical cut-off of $21-29 v \geq 30,1.20$ (1.15 to 1.26) for $10-20 v \geq 30,1.23$ (1.20 to 1.26) for $<10 v \geq 30$, and 1.19 (1.18 to 1.21) per $10 \mathrm{ng} / \mathrm{mL}$ decrease 


\begin{tabular}{|c|c|c|c|c|c|}
\hline Subgroups & $\begin{array}{l}\text { No of } \\
\text { studies }\end{array}$ & $\begin{array}{c}\text { No of } \\
\text { participants }\end{array}$ & $\begin{array}{c}\text { No of } \\
\text { deaths }\end{array}$ & $\begin{array}{c}\text { Relative risk } \\
\quad(95 \% \mathrm{CI})\end{array}$ & $\begin{array}{c}\text { Relative risk } \\
(95 \% \mathrm{Cl})\end{array}$ \\
\hline \multicolumn{6}{|l|}{ Latitude of study location } \\
\hline $140^{\circ} \mathrm{N}, 140^{\circ} \mathrm{S}$ & 10 & 47695 & 3917 & $\longrightarrow$ & $1.41(1.07$ to 1.86$)$ \\
\hline Between $40^{\circ} \mathrm{N}$ and $40^{\circ} \mathrm{S}$ & 9 & 32967 & 2499 & $\rightarrow-$ & 1.29 (1.09 to 1.53$)$ \\
\hline \multicolumn{6}{|l|}{ Average age of participants } \\
\hline$<70$ years & 12 & 69478 & 5217 & $\longrightarrow$ & $1.28(1.09$ to 1.51$)$ \\
\hline$\geq 70$ years & 7 & 11184 & 1199 & & 1.41 (1.01 to 1.96$)$ \\
\hline \multicolumn{6}{|l|}{ Sex } \\
\hline Male & 2 & 2684 & 306 & $\longrightarrow$ & 1.55 (1.05 to 2.27$)$ \\
\hline Female & 2 & 3900 & 142 & $\longrightarrow$ & $1.15(0.81$ to 1.63$)$ \\
\hline Both & 15 & 74078 & 5968 & $\longrightarrow$ & $1.36(1.11$ to 1.67$)$ \\
\hline \multicolumn{6}{|c|}{ Baseline vitamin D supplement uset } \\
\hline$\geq 10 \%$ & 4 & 18187 & 1340 & + & $1.12(0.94$ to 1.32$)\}$ \\
\hline None or $<10 \%$ & 1 & 1194 & 196 & & $1.70(0.96$ to 3.00$) \int$ \\
\hline \multicolumn{6}{|l|}{ Sample type } \\
\hline Plasma & 2 & 11364 & 1718 & $\rightarrow-$ & $1.41(1.24$ to 1.61$)$ \\
\hline Serum & 17 & 69298 & 4698 & $\longrightarrow$ & 1.34 (1.08 to 1.64$)$ \\
\hline \multicolumn{6}{|l|}{ Assay method } \\
\hline Radioimmunoassay & 9 & 36340 & 2481 & $\longrightarrow$ & $1.47(1.11$ to 1.95$)$ \\
\hline Automated assay & 5 & 29044 & 3027 & $\longrightarrow$ & 1.21 (0.93 to 1.58$)$ \\
\hline Chromatographic plus CBP & 3PA 5 & 15278 & 908 & $\longrightarrow$ & $1.22(0.99$ to 1.51$)$ \\
\hline \multicolumn{6}{|l|}{ Average follow-up } \\
\hline$\geq 5$ years & 17 & 72069 & 5806 & $\longrightarrow$ & 1.31 (1.09 to 1.59$)$ \\
\hline$<5$ years & 2 & 8593 & 610 & & 1.70 (0.90 to 3.22$)$ \\
\hline \multicolumn{6}{|l|}{ No of events ascertained } \\
\hline$\geq 500$ & 5 & 37943 & 4276 & $\rightarrow$ & 1.31 (1.09 to 1.58$)$ \\
\hline$<500$ & 14 & 42719 & 2140 & $\longrightarrow$ & $1.36(1.04$ to 1.77$)$ \\
\hline \multicolumn{6}{|l|}{ Level of adjustment } \\
\hline+++ & 9 & 46923 & 3988 & $\longrightarrow$ & $1.26(1.04$ to 1.54$)$ \\
\hline$++/+$ & 10 & 33739 & 2428 & $\longrightarrow$ & 1.40 (1.07 to 1.83$)$ \\
\hline \multicolumn{6}{|l|}{ Controlled for seasonality } \\
\hline Yes & 15 & 68987 & 6038 & $\longrightarrow-$ & 1.31 (1.08 to 1.61$)$ \\
\hline No & 4 & 11675 & 378 & & 1.53 (0.95 to 2.49$)$ \\
\hline \multicolumn{6}{|c|}{ Adjusted for socioeconomic status } \\
\hline Yes & 12 & 56643 & 3908 & $\longrightarrow$ & $1.40(1.09$ to 1.80$)$ \\
\hline No & 7 & 24019 & 2528 & $\longrightarrow-$ & $1.26(0.97$ to 1.63$)$ \\
\hline \multicolumn{6}{|l|}{ Risk of bias score } \\
\hline 9 & 6 & 34661 & 3332 & $\longrightarrow$ & $1.29(1.02$ to 1.64$)$ \\
\hline \multirow[t]{3}{*}{$<9$} & 13 & 46001 & 3084 & $\longrightarrow$ & $1.37(1.06$ to 1.76$)$ \\
\hline & & & 0.751 & $\begin{array}{lll}1 & 1.75 & 2.5\end{array}$ & 3.5 \\
\hline & & & $\begin{array}{l}\text { Relat } \\
\text { ver } \\
25 \text {-hy }\end{array}$ & $\begin{array}{l}\text { erisk }(95 \% \mathrm{Cl}) \text { for bo } \\
\text { us top thirds of basel } \\
\text { oxyvitamin D concent }\end{array}$ & $\begin{array}{l}\text { ine } \\
\text { tration }\end{array}$ \\
\hline
\end{tabular}

Fig 3 Association of circulating 25-hydroxyvitamin D concentration and risk of cardiovascular disease mortality in primary prevention cohorts, according to various characteristics. Based on available studies with relevant subgroup information. $\mathrm{CPBA}=$ competitive binding protein assay; $+=$ relative risks adjusted for established cardiovascular risk factors such as age, sex, smoking status, lipids, hypertension, history of cardiometabolic disease; ++=adjusted for other potential risk factors such as physical activity, body mass index, social status; +++=adjusted for other additional variables such as bone minerals. ${ }^{*} \mathrm{P}<0.05$ from meta-regression analyses. †Based on available studies with relevant subgroup information. $\ddagger$ Based on Newcastle-Ottawa scale. 


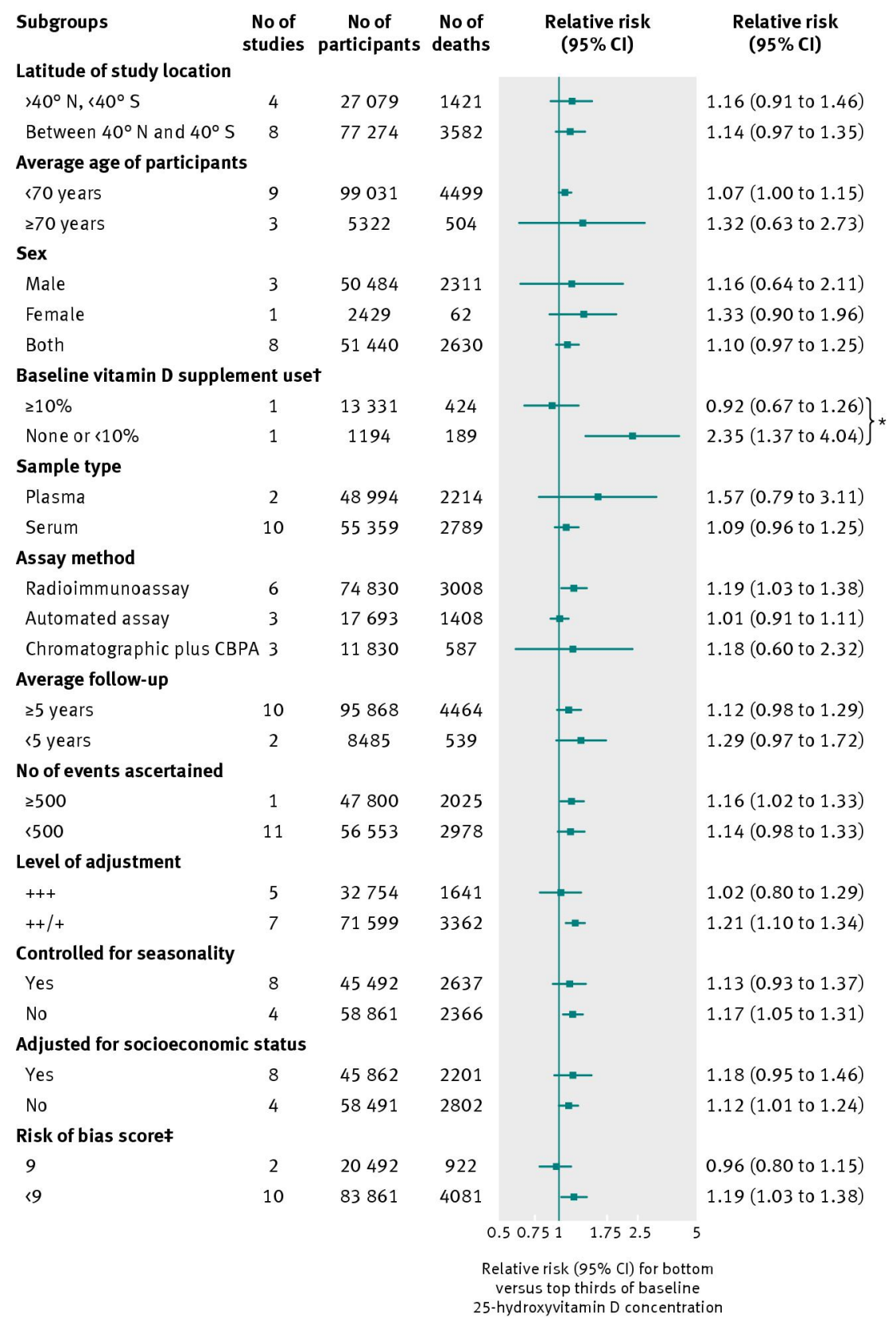

Fig 4 Association of circulating 25-hydroxyvitamin D concentration and risk of cancer mortality in primary prevention cohorts, according to various characteristics. Based on available studies with relevant subgroup information. CPBA=competitive binding protein assay; +=relative risks adjusted for established cardiovascular risk factors such as age, sex, smoking status, lipids, hypertension, history of cardiometabolic disease; ++=adjusted for other potential risk factors such as physical activity, body mass index, social status; +++=adjusted for other additional variables such as bone minerals. ${ }^{*} P<0.05$ from meta-regression analyses. †Based on available studies with relevant subgroup information. ¥Based on Newcastle-Ottawa scale. 


\begin{tabular}{|c|c|c|c|c|c|}
\hline Subgroups & $\begin{array}{l}\text { No of } \\
\text { studies }\end{array}$ & $\begin{array}{c}\text { No of } \\
\text { participants }\end{array}$ & $\begin{array}{c}\text { No of } \\
\text { deaths }\end{array}$ & $\begin{array}{c}\text { Relative risk } \\
(95 \% \mathrm{Cl})\end{array}$ & $\begin{array}{c}\text { Relative risk } \\
\quad(95 \% \mathrm{Cl})\end{array}$ \\
\hline \multicolumn{6}{|l|}{ Latitude of study location } \\
\hline$>40^{\circ} \mathrm{N},<40^{\circ} \mathrm{S}$ & 16 & 295232 & 27646 & $\rightarrow$ & 1.30 (1.18 to 1.42$)$ \\
\hline Between $40^{\circ} \mathrm{N}$ and $40^{\circ} \mathrm{S}$ & 11 & 485758 & 20842 & $\longrightarrow$ & 1.35 (1.16 to 1.57$)$ \\
\hline \multicolumn{6}{|l|}{ Average age of participants } \\
\hline$<70$ years & 17 & 767453 & 44040 & $\rightarrow-$ & 1.35 (1.19 to 1.54$)$ \\
\hline$\geq 70$ years & 10 & 13537 & 4448 & $\longrightarrow$ & 1.33 (1.16 to 1.52$)$ \\
\hline \multicolumn{6}{|l|}{ Sex } \\
\hline Male & 3 & 3466 & 1096 & $\longrightarrow$ & 1.36 (0.91 to 2.05$)$ \\
\hline Female & 4 & 6627 & 522 & $\longrightarrow$ & 1.21 (0.91 to 1.61$)$ \\
\hline Both & 20 & 770897 & 46870 & $\rightarrow$ & 1.37 (1.22 to 1.53$)$ \\
\hline \multicolumn{6}{|c|}{ Baseline vitamin D supplement uset } \\
\hline$\geq 10 \%$ & 8 & 23169 & 4299 & $\rightarrow-$ & 1.25 (1.13 to 1.38$)\}$ \\
\hline None or $<10 \%$ & 3 & 424414 & 12993 & - & $1.80(1.72$ to 1.88$)\}$ \\
\hline \multicolumn{6}{|l|}{ Sample type } \\
\hline Plasma & 4 & 13910 & 8118 & $\longrightarrow$ & 1.34 (1.18 to 1.52$)$ \\
\hline Serum & 23 & 767080 & 40370 & $\rightarrow-$ & 1.34 (1.19 to 1.51$)$ \\
\hline \multicolumn{6}{|l|}{ Assay method } \\
\hline Radioimmunoassay & 11 & 33314 & 4649 & $\longrightarrow-$ & 1.28 (1.11 to 1.47$)$ \\
\hline Automated assay & 7 & 728695 & 39712 & $\longrightarrow$ & 1.39 (1.15 to 1.68$)$ \\
\hline Chromatographic plus $\mathrm{CB}$ & BPA 9 & 18981 & 4127 & $\longrightarrow$ & 1.33 (1.17 to 1.51 ) \\
\hline \multicolumn{6}{|l|}{ Average follow-up } \\
\hline$\geq 5$ years & 22 & 71673 & 17618 & $\rightarrow$ & 1.26 (1.16 to 1.36$)$ \\
\hline$<5$ years & 5 & 709317 & 30870 & $\rightarrow$ & 1.63 (1.44 to 1.84$)\}$ \\
\hline \multicolumn{6}{|l|}{ No of events ascertained } \\
\hline$\geq 500$ & 14 & 758654 & 46162 & $\longrightarrow-$ & 1.34 (1.17 to 1.52$)$ \\
\hline$<500$ & 13 & 22336 & 2326 & $\longrightarrow-$ & 1.35 (1.17 to 1.56$)$ \\
\hline \multicolumn{6}{|l|}{ Level of adjustment } \\
\hline+++ & 10 & 47824 & 13666 & $\rightarrow$ & $1.22(1.11$ to 1.33$)$ \\
\hline$++/+$ & 17 & 733166 & 34822 & $\rightarrow-$ & $1.42(1.26$ to 1.60$)$ \\
\hline \multicolumn{6}{|l|}{ Controlled for seasonality } \\
\hline Yes & 20 & 738356 & 45365 & $\rightarrow-$ & 1.38 (1.22 to 1.56$)$ \\
\hline No & 7 & 42634 & 3123 & $\longrightarrow$ & 1.27 (1.05 to 1.55$)$ \\
\hline \multicolumn{6}{|c|}{ Adjusted for socioeconomic status } \\
\hline Yes & 17 & 481332 & 22014 & $\longrightarrow-$ & $1.43(1.23$ to 1.67$)$ \\
\hline No & 10 & 299658 & 26474 & $\rightarrow$ & 1.24 (1.10 to 1.39$)$ \\
\hline \multicolumn{6}{|l|}{ Risk of bias scoref } \\
\hline 9 & 7 & 282422 & 26767 & - & $1.26(1.20$ to 1.32$)$ \\
\hline \multirow[t]{3}{*}{$<9$} & 20 & 498568 & 21721 & $\longrightarrow$ & 1.39 (1.21 to 1.59$)$ \\
\hline & & & 0.75 & 1.75 & 2.5 \\
\hline & & & $\begin{array}{r}\text { Relat } \\
\text { ver } \\
25 \text {-hy }\end{array}$ & $\begin{array}{l}(95 \% \mathrm{Cl}) \mathrm{fo} \\
\text { thirds of b } \\
\text { amin } \mathrm{D} \text { con }\end{array}$ & \\
\hline
\end{tabular}

Fig 5 Association of circulating 25-hydroxyvitamin D concentration and risk of all cause mortality in primary prevention cohorts, according to various characteristics. Based on available studies with relevant subgroup information.

$\mathrm{CPBA}=$ competitive binding protein assay; $+=$ relative risks adjusted for established cardiovascular risk factors such as age, sex, smoking status, lipids, hypertension, history of cardiometabolic disease; ++=adjusted for other potential risk factors such as physical activity, body mass index, social status; +++=adjusted for other additional variables such as bone minerals. ${ }^{*} \mathrm{P}<0.05$ from meta-regression analyses. †Based on available studies with relevant subgroup information. $\ddagger$ Based on Newcastle-Ottawa scale. 


\begin{tabular}{|c|c|c|c|c|c|c|}
\hline & & \multicolumn{2}{|c|}{ No of participants/deaths } & \multirow{2}{*}{\multicolumn{2}{|c|}{$\begin{array}{c}\text { Relative risk } \\
(95 \% \mathrm{Cl})\end{array}$}} & \\
\hline & $\begin{array}{l}\text { No of } \\
\text { studies }\end{array}$ & $\begin{array}{l}\text { Intervention } \\
\text { group }\end{array}$ & $\begin{array}{l}\text { Control } \\
\text { group }\end{array}$ & & & $\begin{array}{l}\text { Relative risk } \\
(95 \% \mathrm{Cl})\end{array}$ \\
\hline \multicolumn{7}{|c|}{ Trials reporting on vitamin $D_{3}$ alone } \\
\hline Community dwelling & 5 & $3940 / 549$ & $3926 / 601$ & $\rightarrow$ & & 0.91 (0.81 to 1.01$)$ \\
\hline Hospital based & 9 & $2886 / 538$ & $2885 / 576$ & $=$ & & 0.84 (0.65 to 1.09$)$ \\
\hline All studies & 14 & $6826 / 1087$ & $6811 / 1177$ & $\rightarrow$ & & 0.89 (0.80 to 0.99$)$ \\
\hline \multicolumn{7}{|c|}{ Trials reporting on vitamin $\mathrm{D}_{2}$ alone } \\
\hline Community dwelling & 4 & $8313 / 1420$ & $8408 / 1393$ & - & & $1.05(0.94$ to 1.17$)$ \\
\hline Hospital based & 4 & $180 / 20$ & $178 / 17$ & & & $1.15(0.63$ to 2.11$)$ \\
\hline \multirow[t]{3}{*}{ All studies } & 8 & $8493 / 1440$ & $8586 / 1410$ & + & & $1.04(0.97$ to 1.11$)$ \\
\hline & & & & 0.751 & 1.752 & \\
\hline & & & & $\begin{array}{l}\text { Vitamin D } \\
\text { supplement } \\
\text { better }\end{array}$ & $\begin{array}{l}\text { Control } \\
\text { better }\end{array}$ & \\
\hline
\end{tabular}

Fig 6 Effects of vitamin D supplementation on all cause mortality when given alone, derived from available randomised control trials. *Pooled estimates are based on random effects meta-analysis. Using fixed effects models, for community dwelling, hospital based, and overall population, the estimates were 0.91 (0.81 to 1.01), 0.88 (0.77 to 1.01), and 0.90 (0.82 to 0.98 ) for vitamin $D_{3}$ trials and 1.05 (0.94 to 1.17$), 1.15$ (0.63 to 2.11$)$, and 1.03 (0.97 to 1.09$)$ for vitamin $D_{2}$ trials. Overall fixed effect estimate for all trials was 0.98 (0.94 to 1.03). Size of data marker is proportional to inverse of variance of relative risk; horizontal line represents $95 \% \mathrm{Cl}$. Corresponding forest plots and $\mathrm{I}^{2}(95 \% \mathrm{Cl})$ estimates are provided in supplementary material

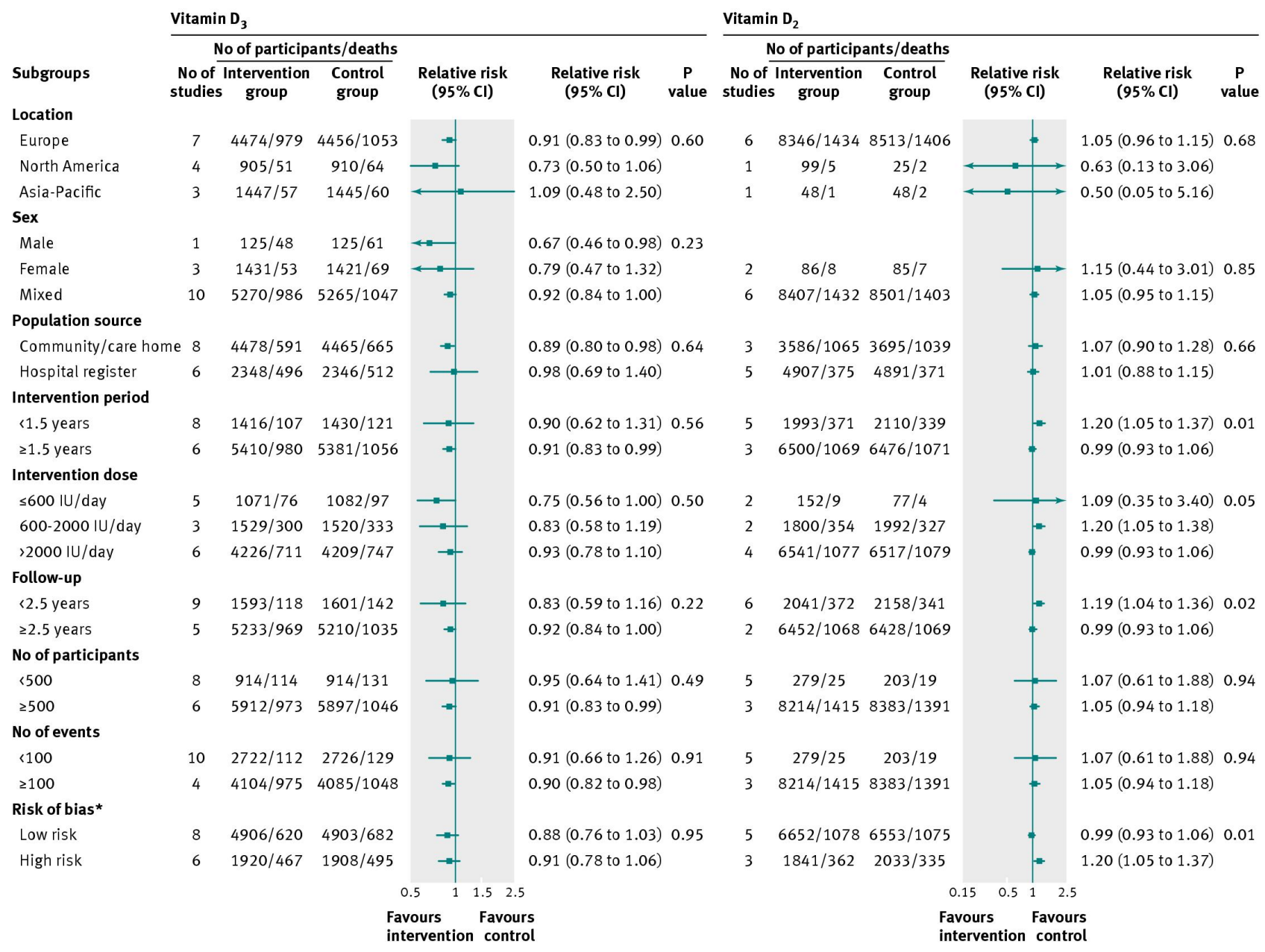

Fig 7 Effects of vitamin D supplementation on all cause mortality, derived from available randomised controlled trials and according to various characteristics. Based on available studies with relevant subgroup information; $P$ values are from meta-regression analyses. *Low risk and high risk categories are defined by studies that met $\geq 5$ criteria versus those that met $<5$ criteria in Cochrane Collaboration's tool, respectively 